\title{
Methylation and expression of miRNAs in precancerous lesions and cervical cancer with HPV16 infection
}

\author{
HILDA JIMÉNEZ-WENCES ${ }^{1}$, DINORAH NASHELY MARTÍNEZ-CARRILLO ${ }^{1}$, OSCAR PERALTA-ZARAGOZA ${ }^{4}$, \\ GABRIELA ELIZABETH CAMPOS-VIGURI ${ }^{1}$, DANIEL HERNÁNDEZ-SOTELO ${ }^{2}$, \\ MARCO ANTONIO JIMÉNEZ-LÓPEZ ${ }^{5}$, JOSÉ GUADALUPE MUÑOZ-CAMACHO ${ }^{5}$, \\ VÍCTOR HUGO GARZÓN-BARRIENTOS ${ }^{5}$, BERENICE ILLADES-AGUIAR ${ }^{3}$ and GLORIA FERNÁNDEZ-TILAPA ${ }^{1}$ \\ ${ }^{1}$ Clinical Research Laboratory, ${ }^{2}$ Virology and Cancer Epigenetics Laboratory and ${ }^{3}$ Molecular Biomedicine Laboratory, \\ Academic Unit of Biological Chemical Sciences, Guerrero Autonomous University, Chilpancingo, Guerrero 39089; \\ ${ }^{4}$ Direction of Chronic Infections and Cancer, Research Center for Infectious Diseases, National \\ Institute of Public Health, Cuernavaca, Morelos $62100 ;{ }^{5}$ Guerrero State Cancer Institute \\ 'Dr Arturo Beltrán Ortega', Acapulco de Juárez, Guerrero 39570, México
}

Received October 29, 2015; Accepted December 8, 2015

DOI: $10.3892 /$ or.2016.4583

\begin{abstract}
Abnormal expression and promoter methylation of microRNAs (miRNAs) are common events during cervical carcinogenesis. Worldwide, infection by types 18 and 16 of human papillomaviruses (HPVs) is considered the major risk factor for cervical cancer development. It has been reported that expression of the miRNAs can be deregulated by specific HPV genotypes. In this study we analyzed the promoter methylation of 22 miRNAs and the expression of three miRNAs in 10 non-squamous intraepithelial lesions (Non-SIL) without HPV16 infection, and 7 Non-SIL, 16 low-grade SIL (LSIL) and 16 cervical cancer samples, all with HPV16 infection. The methylation status was determined using Human Cancer miRNA EpiTect Methyl II Signature PCR Array ${ }^{\circledR}$ and the expression of miR-124, miR-218 and miR-193b was determined by qRT-PCR using individual TaqMan assays. Comparisons of groups defined were performed using the Fisher exact test for categorical variables and Mann-Whitney test for continuous variables. A p-value of $<0.05$ was considered statistically significant. The methylation levels of miR-124-2, miR-218-1, miR-218-2 and miR-34b/c promoters were significantly higher
\end{abstract}

Correspondence to: Dr Gloria Fernández-Tilapa, Clinical Research Laboratory, Academic Unit of Biological Chemical Sciences, Guerrero Autonomous University, Av. Lázaro Cárdenas S/N, Colonia Haciendita, Chilpancingo, Guerrero 39089, México

E-mail: gferti@hotmail.com

Abbreviations: HPVs, human papillomaviruses; miRNAs, microRNAs; SIL, squamous intraepithelial lesions; Non-SIL, non-squamous intraepithelial lesions; LSIL, low-grade SIL; HSIL, high-grade SIL

Key words: miRNAs, methylation, expression, cervical cancer, human papillomavirus 16 in cervical cancer than in LSIL samples. The methylation levels of miR-193b promoter were significantly lower in cervical cancer than in LSIL samples. The expression of miR-124 and miR-218 was significantly lower in cervical cancer than in LSIL samples. The expression of miR-193b was significantly higher in cervical cancer than in LSIL and Non-SIL samples. Our results suggest that the abnormal promoter methylation and expression of miR-124, miR-218 and miR-193b are common events during cervical carcinogenesis.

\section{Introduction}

Cervical cancer is the second most common neoplasia in women worldwide (1). Persistent infection with high-risk human papillomavirus (HR-HPV) is associated with origin and development of this cancer $(2,3)$. Cervical cancer is characterized by the progression of squamous intraepithelial lesions (SIL) of the cervix. Based on their cytopathological characteristics, these lesions are divided into low-grade SIL (LSIL), high-grade SIL (HSIL), and invasive cervical cancer (4). HPV16 is the most prevalent HPV genotype found in invasive cervical cancer worldwide (5), and in México, it is the most frequent genotype found in cervical cancer (6), LSIL and HSIL (7).

The microRNAs (miRNAs) are non-coding RNAs approximately 23 nucleotides long that regulate expression of protein-coding genes via base pairing to the $3^{\prime}$ untranslated region and subsequent induction of degradation, destabilization or translation inhibition of their target mRNAs (8). It has been found that miRNAs regulate the expression of several oncogenes and tumor suppressor genes and their dysregulation is a common feature of human cancers including cervical cancer $(9,10)$. Epigenetic alterations such as aberrant DNA methylation and histone modifications appear to be a major mechanism by which the normal patterns of miRNA expression are disrupted in cancer $(10,11)$. Abnormal promoter methylation of miR-124 family genes has been reported in 
colorectal, breast, lung, liver, renal cancer, and non-Hodgkin's lymphoma (11-13), miR-218 in prostate cancer and oral squamous cell carcinoma $(14,15), \mathrm{miR}-193 \mathrm{~b}$ in prostate and breast cancer $(15,16)$, Similarly, promoter hypermethylation of miR-34 family genes has been found in lung, gastric, breast, and esophageal cancer (17-19).

Few studies have analyzed the methylation of miRNAs in cervical cancer. The methylation of miR-124 family genes has been detected in cervical cancer cell lines SiHa, CaSki and HeLa, as well as in HPV16 and HPV18 immortalized keratinocytes (20). The methylation levels of miR-149, miR-203, miR-375 (21), miR-124a, miR-34b and miR-203 (22) were found to be significantly higher in cervical tumor than in normal tissue. It was also recently found that miRNAs can be regulated specifically by HPV16 or HPV18 in an in vitro model system. Elevated expression of miR-16, miR-25, miR-92a, and miR-378, and the decreased expression of miR-22, miR-27a, miR-29a, and miR-100 could be attributed to viral oncoproteins E6 or E7 of HPV16 and HPV18 (23). In summary, the expression of miRNAs can be regulated specifically by HPV16 or HPV18, however, it is necessary to clarify the mechanism used by these viruses to modulate the expression of specific miRNAs. The abnormal methylation of promoters of miRNA may be involved in the reduction of the expression or its silencing. The objective of this study was to evaluate the methylation of 22 miRNA genes and to determine the level of expression of the differentially methylated miRNAs in cervical tissue of non-squamous intraepithelial lesion (Non-SIL) without HPV16 infection, with precursor lesion and cervical cancers, all with HPV16 infection, with the purpose of verifying the relationship between the methylation status with the level of expression. In this study, the abnormal promoter methylation and the expression of miRNAs were common events during cervical carcinogenesis.

\section{Materials and methods}

Sample collection. We collected cervical smears or cervical biopsies from 146 patients that attended the Guerrero State Cancer Institute, located in Southwestern Southern Mexico between 2012 and 2013. The analysis of miRNA methylation was done only in HPV16-positive samples and in Non-SIL samples without HPV infection: The population consisted of 49 cervical samples; 10 Non-SIL without HPV16 infection, and 7 Non-SIL, 16 LSIL and 16 with cervical cancers, all with HPV16 infection. Exo-endocervical exfoliated cell samples were collected by sampling the ectocervix with an Ayre spatula and endocervix with a cytobrush. Smears were used for cytomorphological examination through conventional Papanicolaou staining. Samples were analyzed by a local, experienced cytopathologist and were classified according to the Bethesda system (24). Women whose cytological diagnosis was Non-SIL a biopsy was not taken. For women diagnosed with LSIL or cervical cancer, a biopsy was obtained for histopathological confirmation of the diagnosis. Two different pathologists performed the diagnosis using the International Federation of Gynecology and Obstetrics (FIGO) classification system (4). All patients signed an informed consent and completed a questionnaire containing demographic and gynecological risk factor data. The study was approved by the Bioethics and Research Committee of the Guerrero State Cancer Institute, and was performed in accordance with the ethical guidelines of the 2008 Helsinki Declaration.

HPV detection and genotyping. Genomic DNA was extracted from cervical scrapes or biopsies by the phenol chloroform method (25). DNA samples were stored at $-20^{\circ} \mathrm{C}$ until used. The concentration and purity of the DNA were evaluated using a NanoDrop 2000c UV-Vis spectrophotometer (Thermo Scientific, Wilmington, DE, USA). Detection and typing of HPV was performed using INNO-LiPA Genotyping Extra kit (Innogenetics, Barcelona, Spain) according to the manufacturer's instructions. Briefly, the DNA samples were subjected to PCR amplification (40 cycles). The PCR products were then denatured, and $10 \mu \mathrm{l}$ of each sample were hybridized onto nitrocellulose strips where the HPV type-specific oligonucleotides were already bound. After $60 \mathrm{~min}$ incubation at $49^{\circ} \mathrm{C}$, the PCR product bound to a specific probe was detected by an alkaline phosphatase-streptavidin conjugate. The INNO-LiPA test allows identification of 13 established HR-HPV types (16, $18,31,33,35,39,45,51,52,56,58,59$, and 66), 5 putative HR-HPV types $(26,53,68,73$, and 82), 7 low-risk HPV types $(6,11,40,43,44,54$, and 70$)$, and 2 types with undefined risk (74 and 69/71).

DNA methylation analysis. DNA methylation levels were evaluated using the Human Cancer miRNA EpiTect Methyl II Signature PCR Array (Qiagen, Germantown, MD, USA) following the manufacturer's protocol. This assay is based on the digestion of unmethylated and methylated DNA, using methylation-sensitive and methylation-dependent restriction enzymes. The remaining DNA after digestion is added to the array and ABI 7500 Real-Time PCR (Applied Biosystems, Foster City, CA, USA) instrument was used to read the plates. The relative amount of methylated and unmethylated DNA was calculated using a standard $\Delta \mathrm{Ct}$ method, normalizing the amount of DNA in each digestion against the total amount of input DNA in the mock digest, using the manufacturer supplied Excel macro-spreadsheet.

Total RNA isolation and expression levels of miR-124, miR-218 and miR-193b. Total RNA was extracted using TRIzol (Invitrogen, Carlsbad, CA, USA) according to the manufacturer's instructions. The concentration and purity of RNA were evaluated using a NanoDrop 2000c UV-Vis spectrophotometer (Thermo Scientific). The reverse transcription was carried out using $10 \mathrm{ng}$ of total RNA. Expression of miR-124 (001182), miR-218 (000521) and miR-193b (002367) was measured using TaqMan microRNA assays following the manufacturer's instructions (Applied Biosystems) in an Applied Biosystems 7500 Real-Time PCR system. Expression of miR-92a (000431) was used as an internal reference for miR-124, miR-218 and miR-193b expression. The relative expression of both miRNAs was analyzed by comparative $\mathrm{Ct}$ method (26).

Statistical analysis. Statistical analysis was performed using the STATA 10.0 software package (Stata Corporation, College Station, TX, USA). Comparisons of groups defined were performed using the Fisher's exact test for categorical 


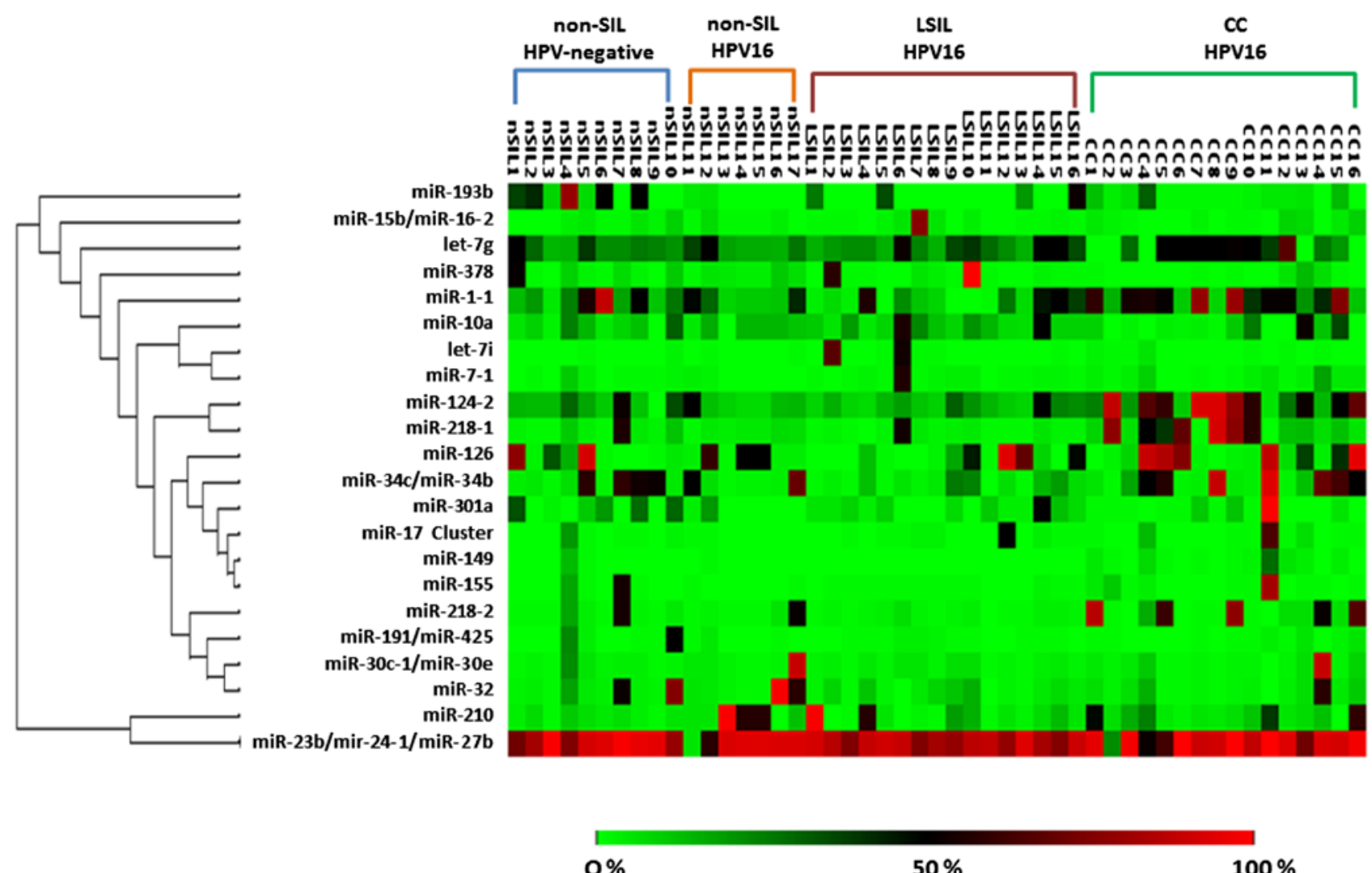

$0 \%$

Figure 1. Heat map diagram of the promoter methylation analysis of 22 miRNAs in cervical samples. The diagram shows the unsupervised hierarchical clustering of the 22 miRNAs according to their promoter methylation status. Each row represents a miRNA and each column represents a sample. The color scale shown at the bottom illustrates the relative methylation level of a miRNA: red, a high methylation level, and green, a low methylation level. Non-SIL, non-squamous intraepithelial lesion; LSIL, low-grade squamous intraepithelial lesion; CC, cervical cancer.

variables and Mann-Whitney test for continuous variables. A p-value of $<0.05$ was considered statistically significant.

\section{Results}

The methylation state of 22 genes of miRNAs, was evaluated in 49 cervical samples from women with and without HPV16 infection. Among the 10 women Non-SIL and HPV-negative, the average age was 32.2 years (range 24-42 years) and the seven women Non-SIL and HPV16-positive the age average was 29.9 years (range 22-57 years). All patients with LSIL and with cervical cancer were infected with HPV16; in the LSIL group the mean age was 29.9 years (range 19-43 years) and in the cancer group 52.8 years (range 38-86 years). Of the women with cervical cancer, $18.7 \%$ had stage 0 (carcinoma in situ), $6.3 \%$ were stage IB, $6.3 \%$ were stage IIA, $56.3 \%$ were stage IIB, $6.3 \%$ were stage IIIB and the 6.3 were stage IVA.

The methylation status of 22 promoters of miRNA gene was evaluated using the Human Cancer miRNA EpiTect Methyl II Signature PCR Array. Methylation of $\mathrm{CpG}$ islands near the initiation site of the transcription of every primary miRNA (pri-miRNA) was determined. The arrangement includes miRNAs involved in the development of cervical cancer and other types of cancer. These miRNAs have as target messenger RNAs (mRNAs) involved in the transcriptional regulation, cell proliferation and apoptosis. The promoters of these miRNAs have $\mathrm{CpG}$ islands or $\mathrm{CpG}$ sites making them susceptible to epigenetic regulation by methylation.

The heat map diagram shows the hierarchical clustering of genes of miRNAs of all the samples and compares the methylation levels of the 22 genes of miRNAs in different groups (Fig. 1). Differences in the methylation profile of 22 miRNAs in each study group were found and this difference was more evident in cervical cancer compared with the groups Non-SIL and LSIL. The frequency of miRNAs methylated is shown in Table I. The percentage of samples with methylation in miR-124-2, miR-193b, miR-218-1, miR-218-2 and $\mathrm{miR}-34 \mathrm{~b} / \mathrm{c}$ was significantly different between groups. The promoters of miR-124-2, miR-218-1, miR-218-2 and miR-34b/c were most frequently found methylated in cervical cancer. In cervical cancer, $68.8 \%$ of cases had methylation in 1-2 of these genes and 25\% had 3-4 methylated miRNAs ( $\mathrm{p}=0.004)$. The number of methylated genes increases with the degree of lesion (Table II). Moreover, the promoter of miR-193b is frequently found in cervical cancer demethylated and frequently methylated in women Non-SIL and HPV-negative infection $(\mathrm{p}=0.001)$.

Based upon these results we analyzed the methylation levels of 5 miRNAs in the four groups (Fig. 2). We found that the methylation levels of miR-124-2, miR-218-1 and $\mathrm{miR}-34 \mathrm{~b} / \mathrm{c}$ were significantly higher in cervical cancer than in LSIL samples ( $\mathrm{p}=0.002, \mathrm{p}<0.001$ and $\mathrm{p}=0.046$, respectively). 
Table I. Frequency the promoter methylation of 22 of the miRNA genes with oncogene or tumor suppressor functions in cervical samples.

\begin{tabular}{|c|c|c|c|c|c|}
\hline Genes & $\begin{array}{c}\text { Non-SIL } \\
\text { HPV negative } \\
\text { n=10 }(\%)\end{array}$ & $\begin{array}{c}\text { Non-SIL HPV16 } \\
\mathrm{n}=7(\%)\end{array}$ & $\begin{array}{l}\text { LSIL HPV16 } \\
\mathrm{n}=16(\%)\end{array}$ & $\begin{array}{c}\text { CC HPV16 } \\
\mathrm{n}=16(\%)\end{array}$ & P-value \\
\hline let-7g & 80 & 85.7 & 75 & 100 & 0.347 \\
\hline let-7i & 0 & 0 & 12.5 & 0 & 0.510 \\
\hline miR-10a & 22.2 & 16.7 & 31.3 & 27.3 & 0.962 \\
\hline miR-1-1 & 70 & 42.9 & 46.2 & 80 & 0.193 \\
\hline miR-124-2 & 44.44 & 14.3 & 37.5 & 81.3 & 0.010 \\
\hline miR-126 & 42.9 & 42.9 & 50 & 46.47 & 1.000 \\
\hline miR-149 & 0 & 0 & 0 & 7.14 & 1.000 \\
\hline miR-155 & 20 & 0 & 0 & 12.5 & 0.268 \\
\hline miR-15b, miR-16-2 & 0 & 0 & 6.25 & 0 & 1.000 \\
\hline miR-17 cluster & 10 & 0 & 6.25 & 6.25 & 1.000 \\
\hline miR-191, miR-425 & 20 & 0 & 0 & 6.67 & 0.175 \\
\hline miR-193b & 57.1 & 33.3 & 80 & 7.1 & 0.001 \\
\hline miR-210 & 0 & 50 & 28.6 & 33.3 & 0.085 \\
\hline miR-218-1 & 10 & 0 & 6.3 & 43.8 & 0.021 \\
\hline miR-218-2 & 30 & 14.3 & 0 & 42.9 & 0.016 \\
\hline miR-23b, miR-24-1, miR-27b & 100 & 85.7 & 100 & 93.8 & 0.306 \\
\hline miR-301a & 50 & 50 & 8.3 & 8.3 & 0.074 \\
\hline miR-30c-1, miR-30e & 10 & 14.3 & 0 & 6.67 & 0.429 \\
\hline miR-32 & 20 & 28.57 & 0 & 6.7 & 0.124 \\
\hline $\operatorname{miR}-34 c$, miR-34b & 40 & 28.6 & 6.25 & 50 & $\mathbf{0 . 0 3 3}$ \\
\hline $\operatorname{miR}-32$ & 20 & 28 & 0 & 6.7 & 0.124 \\
\hline $\operatorname{miR}-378$ & 0 & 0 & 13.3 & 7.69 & 0.874 \\
\hline miR-7-1 & 0 & 0 & 6.3 & 0 & 1.00 \\
\hline
\end{tabular}

Non-SIL, non-squamous intraepithelial lesion; LSIL, low grade squamous intraepithelial lesion; CC, cervical cancer; HPV, human papillomavirus. P-value was calculated with Fisher's exact test. Statistically significant differences are indicated in bold.

Table II. Cervical samples with methylation at 1-4 miRNAs (miR-124-2, miR-218-1, miR-218-2 and miR-34b/c), were found differentially methylated between the study groups.

\begin{tabular}{|c|c|c|c|c|c|}
\hline Genes differentially methylated & $\begin{array}{c}\text { Non-SIL } \\
\text { HPV negative } \\
\text { n=10 }(\%)\end{array}$ & $\begin{array}{c}\text { Non-SIL HPV16 } \\
\mathrm{n}=7(\%)\end{array}$ & $\begin{array}{l}\text { LSIL HPV16 } \\
\mathrm{n}=16(\%)\end{array}$ & $\begin{array}{c}\text { CC HPV16 } \\
\mathrm{n}=16(\%)\end{array}$ & P-value \\
\hline 0 & $4(40)$ & $5(71.4)$ & $10(62.5)$ & $1(6.2)$ & 0.004 \\
\hline $1-2$ & $4(40)$ & $2(28.6)$ & $6(37.5)$ & $11(68.8)$ & \\
\hline $3-4$ & $2(20)$ & 0 & 0 & $4(25)$ & \\
\hline
\end{tabular}

Non-SIL, non-squamous intraepithelial lesion; LSIL, low grade squamous intraepithelial lesion; CC, cervical cancer; HPV, human papillomavirus. P-value was calculated with Fisher's exact test. Statistically significant differences are indicated in bold.

Higher levels of methylation of miR-218-2 were found in cervical cancer than in LSIL, however, the difference was not significant $(\mathrm{p}=0.071)$. The methylation level of $\mathrm{miR}-193 \mathrm{~b}$ was significantly lower in cervical cancer than in LSIL $(p=0.006)$ and Non-SIL samples without HPV16 infection $(\mathrm{p}=0.007)$.

Finally, we evaluated the expression of miR-124, miR-218 and miR-193b in the three sample groups. The expression of
miR-124 was significantly lower in cervical cancer than in LSIL samples $(\mathrm{p}=0.042)$ and Non-SIL $(\mathrm{p}=0.020)$. The expression of miR-218 was significantly lower in cervical cancer than in LSIL samples ( $p=0.001)$. The expression levels of miR-193b increased according to the degree of the lesion and was significantly higher in cervical cancer than in LSIL $(p=0.004)$ Non-SIL without HPV16 infection $(\mathrm{p}=0.002)$ and Non-SIL 

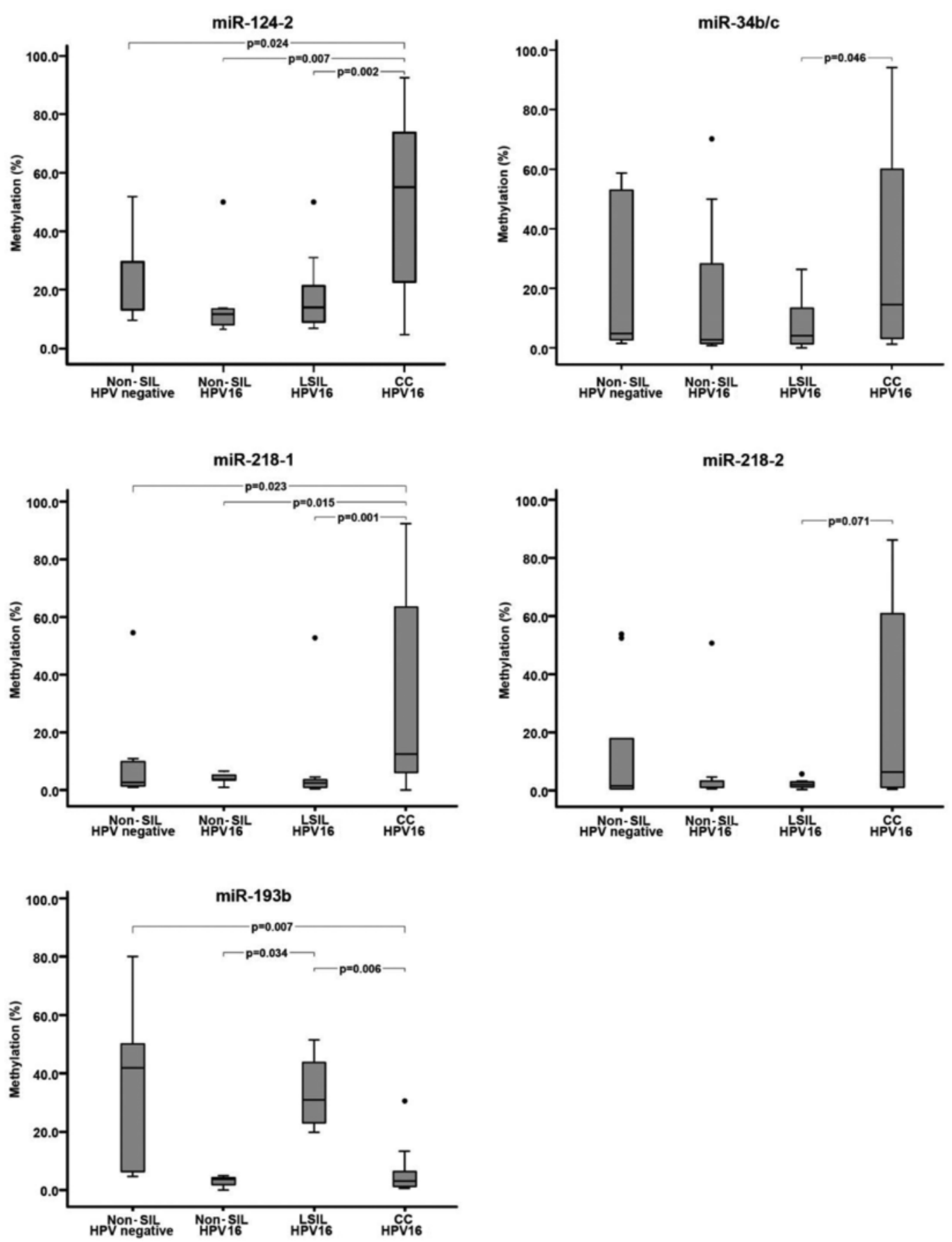

Figure 2. Methylation levels of five miRNAs in cervical samples. The methylation levels were determined in non-squamous intraepithelial lesions (Non-SIL, $\mathrm{n}=10$ ), Non-SIL with HPV16 infection ( $\mathrm{n}=7$ ), low-grade squamous intraepithelial lesions with HPV16 infection (LSIL, $\mathrm{n}=16$ ), and cervical cancer with HPV16 infection $(\mathrm{CC}, \mathrm{n}=16)$. Average methylation level for each group is indicated as a horizontal line. P-value was calculated with Mann-Whitney test and is indicated when the differences are significant. ${ }^{*} \mathrm{p}<0.05$.

with HPV16 (p=0.013) (Fig. 3). The level of methylation had a negative correlation with the expression level of miR-124-2, miR-218-1, miR-218-2 and miR-193b, however, there is no significant difference $(\mathrm{p}=0.966, \mathrm{p}=0.083, \mathrm{p}=0.138$ and 0.099 , respectively) (Fig. 4).

\section{Discussion}

In this study, we analyzed the promoter methylation status of 22 miRNAs. We limited the analysis to HPV16 positive samples, because it is the most frequent HPV genotype detected in precursor lesions and cervical cancer in México $(6,7)$. We found that methylation of miR-124-2, miR-218-1, miR-218-2, $\mathrm{miR}-34 \mathrm{c} / \mathrm{b}$ and the demethylation of miR-193b is an event common in women with cervical cancer compared to women with Non-SIL and LSIL.

The miR-124-2 gene was found methylated in $81.3 \%$ of the cervical cancer samples and the methylation level was significantly higher in this group (methylation levels averaged $50.4 \%$ ), than in women with Non-SIL or LSIL. Interestingly, the expression of miR-124-2 was lower in cancer than in LSIL $(\mathrm{p}=0.042)$. In agreement with these data, we also found that 

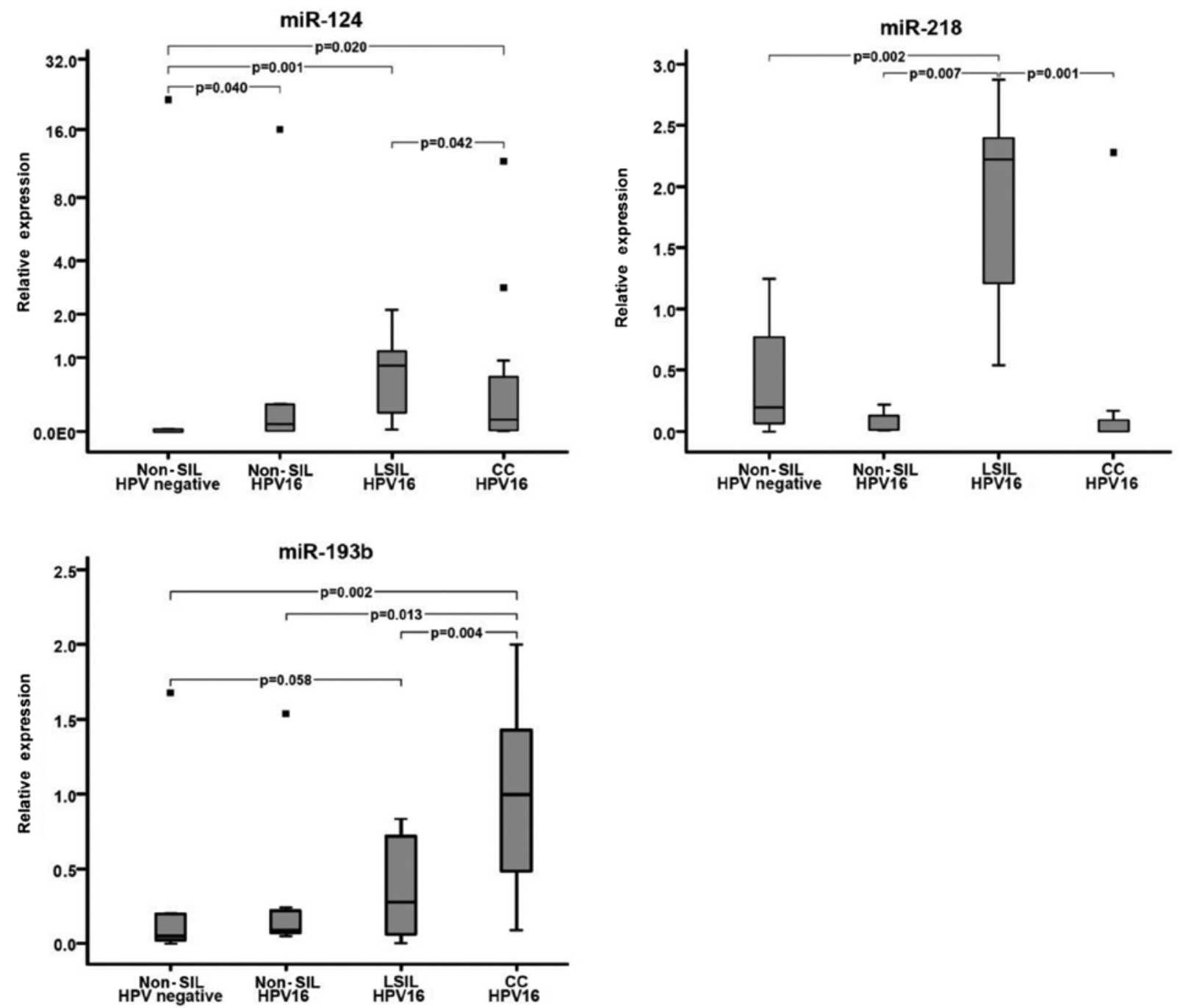

Figure 3. Expression of miR-124, miR-218 and mir-193b in cervical samples. The expression levels were determined in non-squamous intraepithelial lesions (Non-SIL), Non-SIL with HPV16 infection, low grade squamous intraepithelial lesions with HPV16 infection (LSIL), and cervical with HPV16 infection (CC). Average expression level per group is indicated as a horizontal line. P-value was calculated with Mann-Whitney test and is indicated when the differences are significant. " $\mathrm{p}<0.05$.

the expression of miR-124 was significantly lower in cervical cancer than in LSIL samples. The frequency of methylation of miR-124-2 found in this study is higher than those reported in other types of cancer, $50-60 \%$ of the cases $(12,28,29)$. Only in colon cancer, miR-124-2 was methylated in $96.6 \%$ of the cases (30). The methylation of this miRNA in cervical cancer cell lines SiHa, CaSki, HeLa, cervical adenocarcinoma and cell squamous carcinoma has been previously reported by Wilting et al (20), who found the methylation of miR-124-2 in $82.8 \%$ of the cervical cancer cases, consistent with our results. The high frequency and level of promoter methylation of miR-124-2 as well as low or null expression of miR-124 is found in samples of cervical cancer and cell lines compared with Non-SIL and LSIL cases, suggests that methylation of miR-214-2 occurs in late stage of cervical carcinogenesis and that miR-124 may possess tumor suppressive function in this cancer type. The function of miR-124 as tumor suppressor in cervical cancer is supported because ectopic expression of miR-124 significantly decreased the proliferation rate in $\mathrm{SiHa}$ and CaSki cells, and decreased the migratory potential in $\mathrm{SiHa}$ cells (20). The function of miR-124 as tumor suppressor in cervical cancer could be partially explained by its effect on the regulation of the expression of IGFBP-7 mRNA (insulin-like growth factor-binding protein 7), which has been identified as a potential target of miR-124 in cervical cancer (20) and that IGFBP-7 influences the persistence of HR-HPV infection (27).

$\mathrm{miR}-34 \mathrm{~b} / \mathrm{c}$ was found methylated in $50 \%$ of the cervical cancer samples and the methylation level was significantly higher in these patients (average methylation level of 32.7\%) than in LSIL. The frequency of samples with methylation in the promoter of $\mathrm{miR}-34 \mathrm{~b} / \mathrm{c}$ are higher than those reported in other cancers with a frequency between $8-35 \%$, similar to those found in lung and breast cancer (54 and 69\%, respectively) (31). In primary colorectal tumors the methylation of $\mathrm{miR}-34 \mathrm{~b} / \mathrm{c}$ was found in $90 \%$ of cases (32). It is possible that the promoter methylation of $\mathrm{miR}-34 \mathrm{~b} / \mathrm{c}$ in cervical cancer is related to the stage of the disease since, women with cervical cancer methylation in miR-34b/c gene, $12.5 \%$ had stage $0,25 \%$ had stage IIB, $6.25 \%$ had stage IIIB and $6.25 \%$ had stage IVA. The low expression of miR-34b/c in cancer has been associated with metastatic processes and with a more aggressive course of the disease (23). A larger scale study is necessary including 

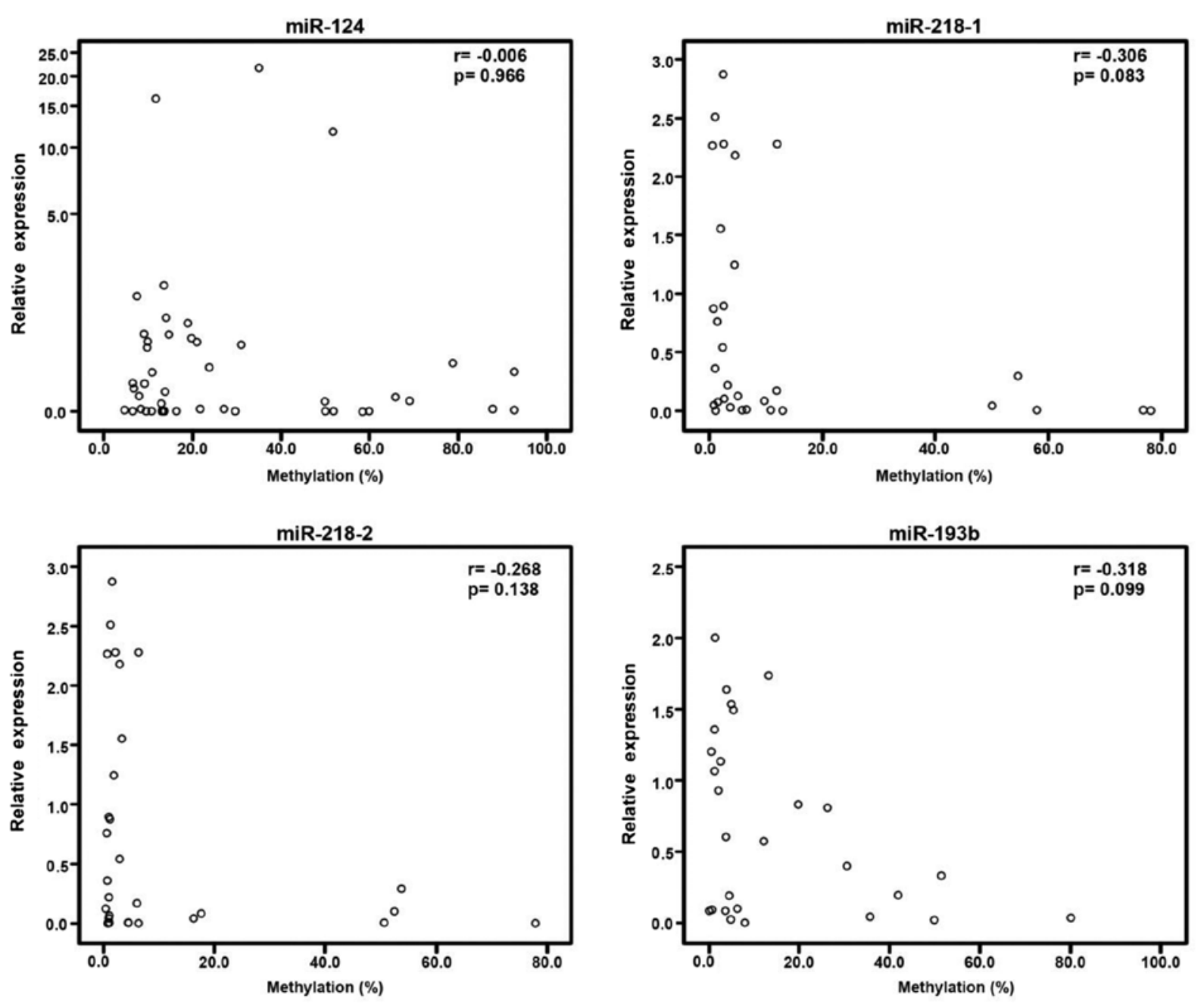

Figure 4. Pearson's correlation between expression and methylation in cervical samples. For miR-124: $r=-0.006, p=0.966$, miR-218-1: $r=-0.306$, $p=0.083$, miR-218-2: $\mathrm{r}=-0.268, \mathrm{p}=0.138$ and miR-193b: $\mathrm{r}=-0.318, \mathrm{p}=0.099$.

includes all the stages of cancer in order to investigate the role of methylation of $\mathrm{miR}-34 \mathrm{~b} / \mathrm{c}$ in carcinogenesis.

miR-218-1 was found methylated in $43.8 \%$ of the cervical cancer samples and demethylated in all Non-SIL and LSIL cases. Methylation level was significantly higher in patients with cervical cancer (with average level of $32.9 \%$ of methylation). The expression levels of miR-218 were significantly lower in cancer compared with LSIL $(\mathrm{p}=0.001)$. In previous studies, it was demonstrated that the expression of miR-218 is decreased in several types of cancer and is associated with malignant phenotypes. In thyroid cancer and cervical cancer cells miR-218 has been characterized as a tumor suppressor miRNA, which is known to inhibit proliferation, invasion and migration $(33,34)$. In cervical cancer, Martinez et al (35) reported that E6 oncoprotein of HPV16 reduces the expression of miR-218 and that LAMB3 is a target of miR-218 in cervical cancer cells. Other studies agree that HR-HPV is related to the decrease of the expression of miR-218 (36). The regulation of the expression of miR-218 by methylation is poorly understood, however, it has been observed that treatment with 5'-Aza-CdR induces overexpression of miR-218 (31). To our knowledge, the methylation of miR-218-1 has not been reported in tissues of cervical cancer and our results suggest that, in addition to HR-HPV infection, the alteration in the methylation of miR-218-1 can contribute to the diminution or silencing of miR-218 in cervical cancer.

The methylation of miR-218-2 was infrequent in Non-SIL cases, we found demethylation in LSIL and methylation of $42.9 \%$ in the samples with cervical cancer. The correlation between the methylation levels of miR-218-1 and 218-2 was statistically significant $(\mathrm{r}=0.368, \mathrm{p}=0.011)$ (data not shown). miR-218-1 and miR-218-2 encode the same mature form and the decrease in expression of miR-218 is associated with malignant phenotypes of cancer. It is probable that women with cervical cancer and methylation in the promoter region of miR-218-1 and miR-218-2 have a poor prognosis.

miR-193b was found methylated in $7.1 \%$ of women with cancer, compared with 33.3 to $80 \%$ of women with Non-SIL or LSIL. We found that the methylation level of miR-193b was significantly lower in cervical cancer $(<15 \%)$ than in LSIL and Non-SIL samples, while its expression was significantly higher in cervical cancer than in LSIL ( $\mathrm{p}=0.004)$. To our knowledge, the methylation of miR-193b has not been reported in tissues of cervical cancer and few studies have evaluated the expression level of miR-193b in cervical precancerous lesions and cervical cancer $(35,37,38)$. It has been proposed that miR-193b is epigenetically regulated in metastatic cell lines from skin (IGR37) and head and neck (SIHN-011B) (31), as well as in 
the prostate cancer cell line 22Rv1, and in clinical prostate tumors as compared to benign prostatic hyperplasia (15). In addition to that the expression of this miRNA is restored after treatment with 5'-Aza-CdR and has been identified as a tumor suppressor in cancers $(15,31)$. However, the methylation state of miR-193b in cancer is controversial because it has been found methylated and unmethylated in cell lines of the same type of cancer. In six cell lines, of prostate cancer (22Rv1, VCAP, LNCaP, PC-3, EP156T and the PrEC cells) methylation was found in miR-193b, however, in two cell lines (DU145 and LAPC-4) this miRNA was found demethylated (15), and overexpression of miR-193b in cancer is associated with a poor prognosis (37-40), due to the activation of its target Smad3, which, promotes cell proliferation via the transforming growth factor $\beta$ (TGF- $\beta$ ) (38). In cell lines of cervical cancer with HPV16, miR-193b was found overexpressed in comparison with HPV-negative cell line and normal cervix (35). In agreement with these observations, Cheung et al (37) reported that miR-193b was downregulated in high grade cervical intraepithelial neoplasia (similar to HSIL) when compared to normal cervical epithelium. We found that, miR-193b is overexpressed in cervical cancer, suggesting that it may have oncogenic functions. Our results support the hypothesis that the expression of miR-193b is regulated by methylation and it is likely that in cervical cancer miR-193b acts as an oncogene and that the overexpression of this miRNA is related to a poor prognosis.

It was found that the number of methylated genes and methylation levels increases with the degree of lesion, which in cervical cancer it is probable that the altered methylation of miRNAs is associated with a poor prognosis. Collectively, our results suggest that the expression of miR-124-2, miR-218-1, $\mathrm{miR}-218-2, \mathrm{miR}-34 \mathrm{c} / \mathrm{b}$ and miR-193b is regulated by methylation in cervical cancer associated with HPV16 infection and that it is probable that the alteration in methylation and expression of these miRNAs contribute to the pathogenesis of the disease. The results of this investigation provide information on the state of methylation of miRNA genes in early stages of cancer and in cervical cancer supporting the role of methylation in carcinogenesis associated with HPV16 infection.

\section{Acknowledgements}

Our thanks to Natividad Sales Linares for making the molecular diagnosis of HPV. We also wish to thank Jacobo Zúñiga Castillo, for technical advice for methylation Array. The present study was financed by CONACYT", Convocatoria 2012 de Ciencia Básica, key, 183341 and Guerrero Autonomous University, Convocatoria 2013. During the development of the investigation Hilda Jiménez Wences was a grant recipient of CONACYT.

\section{References}

1. Tao L, Han L, Li X, Gao Q, Pan L, Wu L, Luo Y, Wang W, Zheng $\mathrm{Z}$ and Guo $\mathrm{X}$ : Prevalence and risk factors for cervical neoplasia: A cervical cancer screening program in Beijing. BMC Public Health 14: 1185, 2014.

2. Snijders PJ, Steenbergen RD, Heideman DA and Meijer CJ: HPV-mediated cervical carcinogenesis: Concepts and clinical implications. J Pathol 208: 152-164, 2006.
3. zur Hausen H: Papillomaviruses and cancer: From basic studies to clinical application. Nat Rev Cancer 2: 342-350, 2002.

4. Benedet JL, Bender H, Jones H III, Ngan HY and Pecorelli S; FIGO Committee on Gynecologic Oncology: FIGO staging classifications and clinical practice guidelines in the management of gynecologic cancers. Int J Gynaecol Obstet 70: 209-262, 2000.

5. Guan P, Howell-Jones R, Li N, Bruni L, de Sanjosé S, Franceschi S and Clifford GM: Human papillomavirus types in 115,789 HPV-positive women: A meta-analysis from cervical infection to cancer. Int J Cancer 131: 2349-2359, 2012.

6. Illades-Aguiar B, Cortés-Malagón EM, Antonio-Véjar V, Zamudio-López N, Alarcón-Romero LC, Fernández-Tilapa G, Hernández-Sotelo D, Terán-Porcayo MA, Flores-Alfaro E and Leyva-Vázquez MA: Cervical carcinoma in Southern Mexico: Human papillomavirus and cofactors. Cancer Detect Prev 32: 300-307, 2009.

7. Illades-Aguiar B, Alarcón-Romero LC, Antonio-Véjar V, Zamudio-López N, Sales-Linares N, Flores-Alfaro E, Fernández-Tilapa G, Vences-Velázquez A, Muñoz-Valle JF and Leyva-Vázquez MA: Prevalence and distribution of human papillomavirus types in cervical cancer, squamous intraepithelial lesions, and with no intraepithelial lesions in women from Southern Mexico. Gynecol Oncol 117: 291-296, 2010.

8. Bartel DP: MicroR NAs: Target recognition and regulatory functions. Cell 136: 215-233, 2009.

9. Kinose Y, Sawada K, Nakamura K and Kimura T: The role of microRNAs in ovarian cancer. Biomed Res Int 2014: 249393, 2014.

10. Suzuki H, Maruyama R, Yamamoto E and Kai M: Epigenetic alteration and microRNA dysregulation in cancer. Front Genet 4: 258,2013

11. Lujambio A, Ropero S, Ballestar E, Fraga MF, Cerrato C, Setién F, Casado S, Suarez-Gauthier A, Sanchez-Cespedes M, Git A, et al: Genetic unmasking of an epigenetically silenced microRNA in human cancer cells. Cancer Res 67: 1424-1429, 2007.

12. Furuta M, Kozaki KI, Tanaka S, Arii S, Imoto I and Inazawa J: miR-124 and miR-203 are epigenetically silenced tumor-suppressive microRNAs in hepatocellular carcinoma. Carcinogenesis 31: 766-776, 2010.

13. Gebauer K, Peters I, Dubrowinskaja N, Hennenlotter J, Abbas M, Scherer R, Tezval H, Merseburger AS, Stenzl A, Kuczyk MA, et al: Hsa-mir-124-3 CpG island methylation is associated with advanced tumours and disease recurrence of patients with clear cell renal cell carcinoma. Br J Cancer 108: 131-138, 2013.

14. Uesugi A, Kozaki K, Tsuruta T, Furuta M, Morita K, Imoto I, Omura $\mathrm{K}$ and Inazawa J: The tumor suppressive microRNA miR-218 targets the mTOR component Rictor and inhibits AKT phosphorylation in oral cancer. Cancer Res 71: 5765-5778, 2011.

15. Rauhala HE, Jalava SE, Isotalo J, Bracken H, Lehmusvaara S, Tammela TL, Oja H and Visakorpi T: miR-193b is an epigenetically regulated putative tumor suppressor in prostate cancer. Int J Cancer 127: 1363-1372, 2010.

16. Radpour R, Barekati Z, Kohler C, Schumacher MM, Grussenmeyer T, Jenoe P, Hartmann N, Moes S, Letzkus M, Bitzer J, et al: Integrated epigenetics of human breast cancer: Synoptic investigation of targeted genes, microRNAs and proteins upon demethylation treatment. PLoS One 6: e27355, 2011.

17. Lodygin D, Tarasov V, Epanchintsev A, Berking C, Knyazeva T, Körner H, Knyazev P, Diebold J and Hermeking H: Inactivation of miR-34a by aberrant CpG methylation in multiple types of cancer. Cell Cycle 7: 2591-2600, 2008.

18. Suzuki H, Yamamoto E, Nojima M, Kai M, Yamano HO, Yoshikawa K, Kimura T, Kudo T, Harada E, Sugai T, et al: Methylation-associated silencing of microRNA-34b/c in gastric cancer and its involvement in an epigenetic field defect. Carcinogenesis 31: 2066-2073, 2010.

19. Wang Z, Chen Z, Gao Y, Li N, Li B, Tan F, Tan X, Lu N, Sun Y, Sun J, et al: DNA hypermethylation of microRNA-34b/c has prognostic value for stage I non-small cell lung cancer. Cancer Biol Ther 11: 490-496, 2011.

20. Wilting SM, van Boerdonk RAA, Henken FE, Meijer CJ, Diosdado B, Meijer GA, le Sage C, Agami R, Snijders PJF and Steenbergen RD: Methylation-mediated silencing and tumour suppressive function of hsa-miR-124 in cervical cancer. Mol Cancer 9: 167, 2010.

21. Wilting SM, Verlaat W, Jaspers A, Makazaji NA, Agami R, MeijerCJ, Snijders PJ and Steenbergen RD: Methylation-mediated transcriptional repression of microRNAs during cervical carcinogenesis. Epigenetics 8: 220-228, 2013. 
22. Botezatu A, Goia-Rusanu CD, Iancu IV, Huica I, Plesa A Socolov D, Ungureanu C and Anton G: Quantitative analysis of the relationship between microRNA-124a, -34b and -203 gene methylation and cervical oncogenesis. Mol Med Rep 4: 121-128, 2011.

23. Wang X, Wang HK, Li Y, Hafner M, Banerjee NS, Tang S, Briskin D, Meyers C, Chow LT, Xie X, et al: microRNAs are biomarkers of oncogenic human papillomavirus infections. Proc Natl Acad Sci USA 111: 4262-4267, 2014

24. Solomon D, Davey D, Kurman R, Moriarty A, O'Connor D, Prey M, Raab S, Sherman M, WilburD, Wright T Jr, et al; Bethesda 2001 Workshop: The 2001 Bethesda System: Terminology for reporting results of cervical cytology. JAMA 287: 2114-2119, 2002.

25. Davis LG, Kuehl WM and Battey JF: Basic Methods in Molecular Biology. 2nd edition. Appleton and Lange, Norwalk, CT, pxiv, 1994.

26. Schmittgen TD and Livak KJ: Analyzing real-time PCR data by the comparative C(T) method. Nat Protoc 3: 1101-1108, 2008.

27. Harris TG, Burk RD, Yu H, Minkoff H, Massad LS, Watts DH, Zhong Y, Gange S, Kaplan RC, Anastos K, et al: Insulin-like growth factor axis and oncogenic human papillomavirus natural history. Cancer Epidemiol Biomarkers Prev 17: 245-248, 2008.

28. Kitano K, Watanabe K, Emoto N, Kage H, Hamano E, Nagase T, Sano A, Murakawa T, Nakajima J, Goto A, et al: $\mathrm{CpG}$ island methylation of microRNAs is associated with tumor size and recurrence of non-small-cell lung cancer. Cancer Sci 102: 2126-2131, 2011.

29. Shimizu T, Suzuki H, Nojima M, Kitamura H, Yamamoto E, Maruyama R, Ashida M, Hatahira T, Kai M, Masumori N, et al: Methylation of a panel of microRNA genes is a novel biomarker for detection of bladder cancer. Eur Urol 63: 1091-1100, 2013.

30. Suzuki H, Takatsuka S, Akashi H, Yamamoto E, Nojima M, Maruyama R, Kai M, Yamano HO, Sasaki Y, Tokino T, et al: Genome-wide profiling of chromatin signatures reveals epigenetic regulation of MicroRNA genes in colorectal cancer. Cancer Res 71: 5646-5658, 2011.

31. Lujambio A, Calin GA, Villanueva A, Ropero S, Sánchez-Céspedes M, Blanco D, Montuenga LM, Rossi S, Nicoloso MS, Faller WJ, et al: A microRNA DNA methylation signature for human cancer metastasis. Proc Natl Acad Sci USA 105: 13556-13561, 2008.
32. Toyota M, Suzuki H, Sasaki Y,Maruyama R, Imai K, Shinomura Y and Tokino T: Epigenetic silencing of microRNA-34b/c and B-cell translocation gene 4 is associated with $\mathrm{CpG}$ island methylation in colorectal cancer. Cancer Res 68: 4123-4132, 2008.

33. Yamamoto N, Kinoshita T, Nohata N, Itesako T, Yoshino H, Enokida H, Nakagawa M, Shozu M and Seki N: Tumor suppressive microRNA-218 inhibits cancer cell migration and invasion by targeting focal adhesion pathways in cervical squamous cell carcinoma. Int J Oncol 42: 1523-1532, 2013.

34. Guan H, Wei G, Wu J, Fang D, Liao Z, Xiao H, Li M and Li Y: Down-regulation of miR-218-2 and its host gene SLIT3 cooperate to promote invasion and progression of thyroid cancer. J Clin Endocrinol Metab 98: E1334-E1344, 2013.

35. Martinez I, Gardiner AS, Board KF, Monzon FA, Edwards RP and Khan SA: Human papillomavirus type 16 reduces the expression of microRNA-218 in cervical carcinoma cells. Oncogene 27: 2575-2582, 2008

36. Li Y, Liu J, Yuan C, Cui B, Zou X and Qiao Y: High-risk human papillomavirus reduces the expression of microRNA-218 in women with cervical intraepithelial neoplasia. J Int Med Res 38: 1730-1736, 2010.

37. Zhong Q, Wang T, Lu P, Zhang R, Zou J and Yuan S: miR-193b promotes cell proliferation by targeting Smad3 in human glioma. J Neurosci Res 92: 619-626, 2014.

38. Cheung TH, Man KN, Yu MY, Yim SF, Siu NS, Lo KW, Doran G, Wong RR, Wang VW, Smith DI, et al: Dysregulated microRNAs in the pathogenesis and progression of cervical neoplasm. Cell Cycle 11: 2876-2884, 2012

39. Hu H, Li S, Liu J and Ni B: MicroRNA-193b modulates proliferation, migration, and invasion of non-small cell lung cancer cells. Acta Biochim Biophys Sin (Shanghai) 44: 424-430, 2012.

40. Lenarduzzi M, Hui AB, Alajez NM, Shi W, Williams J, Yue S, O'Sullivan B and Liu FF: MicroRNA-193b enhances tumor progression via down regulation of neurofibromin 1 . PLoS One 8: e53765, 2013. 